\title{
A atuação do professor em programas de educação executiva: o desenvolvimento de executivos efetivos
}

\author{
(Instructors' performance in executive education programs: the development of effective \\ executives)
}

\author{
Karina De Déa Roglio \\ Christianne Coelho de Souza Reinisch Coelho
}

\begin{abstract}
Resumo
Neste artigo, investiga-se a atuação do professor no desenvolvimento da capacidade dos executivos para tomar decisões efetivas em situações inesperadas, complexas e incertas com as quais se defrontam na sua prática profissional. Após identificar elementos críticos na atuação do professor no referencial teórico, buscou-se confirmá-los por meio de uma pesquisa qualitativa em um programa de MBA Executivo. Os dados foram coletados por meio de observação, análise documental e entrevistas com vinte executivos matriculados em um programa de MBA Executivo nos Estados Unidos. O desenvolvimento da capacidade dos executivos para tomar decisões efetivas foi estimulado pelos professores com o uso combinado dos seguintes elementos: (1) aplicação dos princípios da aprendizagem vivencial e da andragogia, que propiciaram um equilíbrio entre o rigor científico e a relevância prática, entre ação e reflexão; (2) características de profissional reflexivo; (3) uso de diferentes estratégias de ensino/aprendizagem; (4) estímulo ao compartilhamento de experiências.
\end{abstract}

Palavras-chave: Educação executiva; Atuação do professor; Executivos efetivos.

\begin{abstract}
This paper investigates instructors' performance in developing executives' decision-making capacity in unexpected, complex, and uncertain situations. After identifying critical elements in instructors' performance in theory, the research attempted to confirm them by means of a qualitative survey with twenty executives from an Executive MBA Program at an American Management School ranked among the top five in the world. Data collection was carried out through observation, documental analysis and interviews. The research findings disclose important elements that need to be seriously considered by instructors and administrators revising and developing successful Executive Education Programs to provide organizations and society with effective executives. According to the executives, the most important elements identified in the instructors' performance are: (1) application of the principles of experiential learning and andragogy, which propitiates a balance between scientific accuracy and practical relevance, action and reflection; (2) characteristics of a reflective professional, (3) the use of diverse teaching-learning strategies, and (4) opportunities for sharing experiences.
\end{abstract}

Key words: Executive education; Instructors' performance; Effective executives.

A educação superior enfrenta grandes desafios para desenvolver profissionais com as competências críticas requeridas por um ambiente que se torna cada vez mais complexo e incerto. Light e Cox (2001), ao analisarem a educação superior, comparam o atual movimento de transição 
na educação a uma tempestade: as condições de incerteza e ambiguidade que permeiam a educação superior produzem a sensação de se estar no meio de uma tempestade que, para ser controlada, "requer a capacidade de se inserir criticamente em um ambiente de incerteza e mudanças substanciais - e gerenciar esse ambiente" (LIGHT; COX, 2001, p. 12). O problema, complementam esses autores, é que não existe nenhum arcabouço sólido de conceitos para dar um sentido a essas mudanças, compreendê-las e identificar caminhos para enfrentá-las à medida que elas tomam forma. Na educação superior, particularmente, vive-se no período da supercomplexidade, no qual os referenciais utilizados para compreender o mundo estão sendo questionados.

Schön (1987) refere-se a uma crise de confiança no conhecimento profissional, gerada pelo dilema entre rigor e relevância. Esse dilema se situa entre a ideia predominante do rigor do conhecimento profissional (baseado na racionalidade técnica) e a realidade complexa que, por apresentar situações inesperadas, incertas e instáveis, não encontra respostas para os seus problemas nos cânones do conhecimento científico. De acordo com o autor, essa crise corresponde a uma crise similar na educação profissional e instiga discussões sobre "a lacuna existente entre a concepção predominante nas escolas sobre o conhecimento profissional e as competências efetivamente requeridas pelos profissionais na esfera da ação" (SCHÖN, 1987, p. 10). Nesse contexto, um modelo mais apropriado para a educação profissional é necessário para estimular os estudantes a se tornarem profissionais reflexivos e, por conseguinte, capazes de lidar com problemas complexos e multifacetados.

Os programas de Educação Executiva, em particular, sofrem críticas por sua dificuldade para desenvolver executivos efetivos, capazes de refletir sobre o inesperado, a incerteza e a complexidade dos ambientes internos e externos às organizações, que constituem um elemento crítico nos processos decisórios. De acordo com Drucker (2004), executivos efetivos tomam decisões efetivas.

\footnotetext{
Executivos efetivos diferem amplamente nas suas personalidades, forças, fraquezas, valores e crenças. Tudo o que têm em comum é que têm as coisas certas feitas. Alguns nascem efetivos. Mas a demanda é muito grande para ser satisfeita por talentos extraordinários. Efetividade é uma disciplina. E, como toda disciplina, efetividade pode ser aprendida e deve ser desenvolvida. (DRUCKER, 2004, p. 63)
}

A efetividade pode ser desenvolvida de formas diferentes e interdependentes: educação formal, educação informal, desenvolvimento pessoal ou uma combinação deles. Neste artigo, considera-se que os programas de Educação Executiva, em particular programas de MBA Executivo, são um campo fértil para o desenvolvimento de executivos efetivos. Dessa forma, nas discussões subsequentes serão consideradas as questões teóricas e práticas inseridas no contexto dos programas de Educação Executiva. 
Bennis e O'Toole (2005) analisaram o dilema entre o rigor e a relevância, discutido por Schön (1987), no contexto da educação executiva e criticaram o modelo da excelência acadêmica, adotado nas melhores escolas de MBA, que consideram o rigor da pesquisa científica como principal fator de avaliação da sua performance. O problema, prosseguem os autores, não é o fato de essas escolas terem adotado o rigor científico, mas o fato de que renunciaram a outras formas de conhecimento. Na sua opinião, é necessário que as escolas de administração busquem o equilíbrio entre o rigor científico e a relevância prática. Ghoshal (2005, p. 77) concorda com os autores ao afirmar: "Nós adotamos a abordagem científica para tentar descobrir padrões e leis, e substituir todas as noções da intencionalidade humana com o firme propósito no determinismo causal para explicar todos os aspectos da performance corporativa".

De acordo com essas perspectivas, a atuação do professor nos programas de Educação Executiva torna-se um elemento essencial para criar e manter um equilíbrio entre o rigor científico e a relevância prática. Afinal, ele/a é um guia do processo de aprendizagem. Neste artigo, investiga-se a atuação do professor no desenvolvimento da capacidade dos executivos para tomar decisões efetivas em situações inesperadas, complexas e incertas com as quais se defrontam na sua prática profissional. Com esse objetivo, procurou-se (1) identificar elementos críticos na atuação do professor que favoreçam o desenvolvimento dessa capacidade em programas de Educação Executiva; (2) analisar, com base em um estudo empírico, a atuação do professor em um programa de MBA Executivo. Esses temas são organizados da seguinte forma: (1) referencial teórico, (2) metodologia de pesquisa, (3) apresentação e discussão dos resultados, (4) conclusões e (5) referências.

\section{A atuação do professor em programas de educação executiva}

Diversos autores apresentaram estudos sobre a efetividade dos processos da educação executiva. Neste artigo, os principais referenciais analisados foram - além dos trabalhos de Bennis e O’Toole (2005) e de Ghoshal (2005) mencionados na introdução - as pesquisas desenvolvidas por Currie e Knights (2003), Gosling e Mintzberg (2003), Grey (2004), G. Smith (2003), P. Smith (2001), Reynolds e Vince (2004) e Schön (1987). Esses autores investigaram diferentes possibilidades para a reestruturação dos processos de aprendizagem em programas de educação executiva e conferiram atenção especial à prática reflexiva como um método valioso na preparação dos executivos para a prática decisória.

No contexto da abordagem disciplinar, observam Currie e Knights (2003), o conhecimento é visto como um objeto que pode ser adquirido e possuído e a certeza inerente ao seu desenvolvimento torna a educação uma questão simples de transmissão da verdade estabelecida e 
acumulada. A abordagem crítica, ao contrário, usa as experiências de trabalho e as experiências pessoais dos estudantes para problematizar em vez de simplesmente validar as concepções e teorias sobre o gerenciamento. A proposta desses autores não significa somente uma forma diferente de ensinar o conhecimento existente sobre gerenciamento, mas uma preocupação em refletir criticamente sobre esse conhecimento, com o objetivo de compreendê-lo como uma prática social, política, econômica e moral.

A percepção de Gosling e Mintzberg (2003, p. 56) é de que o executivo efetivo precisa ser capaz de reunir ação e reflexão, ou seja, encontrar o "ponto em que o pensamento reflexivo encontra a ação prática". Nesse sentido, sugerem uma estrutura diferenciada para os programas de educação executiva, que tem como base o desenvolvimento de cinco formas de pensar: reflexiva (autogestão); analítica (gestão das organizações); global (gestão do contexto); colaborativa (gestão dos relacionamentos); de ação (gestão das mudanças). Na perspectiva de Grey (2004), a educação executiva deveria aprofundar a compreensão dos interesses dos stakeholders sobre a organização e a sociedade mais ampla. De acordo com esse autor, "valores e contextos deveriam ser analisados e discutidos dentro das salas de aula como parte integral dos programas" (GREY, 2004, p. 180).

G. Smith (2003) censurou as abordagens utilizadas em programas de educação executiva para o desenvolvimento do pensamento crítico e do processo decisório e propôs uma perspectiva ampliada denominada "instrução para aprender a pensar" (thinking skills instruction). P. Smith (2001) sugeriu o conceito de "aprendizagem na ação" (action learning). Na opinião de Reynolds e Vince (2004), a educação gerencial e, consequentemente, os gestores poderiam se beneficiar ao unir duas tradições distintas na aprendizagem gerencial: a aplicação de perspectivas críticas para a teoria e a prática de gestão e a aprendizagem baseada na ação (action-based learning). Schön (1987) desenhou a proposta do "ensino prático reflexivo" (reflective practicum) como ferramenta educacional.

Com base nesses estudos, o tema da educação executiva analisada neste artigo é a atuação do professor. Uma ideia comum nesses estudos é que a teoria da aprendizagem vivencial deveria ser considerada pelos professores como uma referência no processo de aprendizagem em função do perfil dos estudantes matriculados em programas dessa natureza.

O processo da aprendizagem vivencial apresentado por Kolb (1984) é representado em um ciclo composto por quatro estágios (adaptive learning modes): (1) experiência concreta; (2) observação e reflexão; (3) formação de conceitos abstratos; (4) experimentação ativa. O autor define a aprendizagem como "o processo por meio do qual o conhecimento é criado com base na transformação da experiência" (KOLB, 1984, p. 38). O conceito da aprendizagem vivencial implica que toda aprendizagem é reaprendizagem (relearning): ninguém ingressa em uma situação de 
aprendizagem sem algumas ideias articuladas a respeito do assunto em questão. Por isso, é essencial que o educador relacione essas ideias ao processo de aprendizagem. Na visão do autor, não faz sentido pensar a educação executiva desconectada da aprendizagem vivencial, porque:

\begin{abstract}
Os interesses de aprendizagem dos adultos estão relacionados com 1. as suas histórias pessoais; 2. a sua visão sobre o seu papel no mundo; 3. a sua percepção sobre o que podem fazer e o que querem fazer. Para eles, os métodos que combinam trabalho e estudo, teoria e prática proporcionam uma arena para a aprendizagem mais familiar e, consequentemente, mais produtiva. (KOLB, 1984, p. 38)
\end{abstract}

Com base nos princípios da aprendizagem vivencial, o professor encoraja os executivos a refletir sobre (1) os modelos mentais aplicados nos seus processos decisórios, (2) as consequências geradas pelas suas decisões sobre os indivíduos, as organizações e a sociedade, e (3) lições que podem ser extraídas dessas consequências. Raelin e Coghlan (2006) observaram que, se a oportunidade para reflexão é combinada com experiências profissionais, os executivos podem perceber a possibilidade de reformular a experiência a partir de uma revisão das suposições que fundamentam o processo decisório. Por meio desse processo reflexivo, eles podem usar a experiência vivida para gerar aprendizagem prática e conhecimento para a ação.

Entretanto, incitar a competência dos executivos para desenvolverem um processo contínuo de reflexão com base na aprendizagem vivencial representa uma tarefa complexa para os professores. De acordo com Meyers (1991, p. 29), "a chave para o movimento do concreto para o abstrato está na ordem desse movimento: concreto primeiro e então a abstração. Essa ideia pode parecer senso comum - mas está em oposição direta aos métodos tradicionais que apresentam abstrações através de algum método concreto de verificação".

Com foco nesse tema e relacionando-o ao desenvolvimento do profissional reflexivo, Schön (1987) apresentou o ensino prático reflexivo (reflective practicum), cujas características principais são "aprender fazendo, coaching ao invés de ensinar e um diálogo recíproco de reflexão-na-ação entre professor e estudante" (p. 303). Nessa proposta, com o objetivo de acentuar o desenvolvimento da prática reflexiva, o professor deve criar um ambiente de aprendizagem ativa que favorece e estimula a capacidade e a motivação dos estudantes para revelar os seus modelos mentais, formular generalizações e cogitar novas possibilidades.

Concomitante à aprendizagem vivencial, é importante que o professor desenhe a sua prática profissional com base nos princípios da andragogia. Knowles (1984) desenvolveu uma estrutura conceitual para a educação de adultos - a andragogia. Knowles, Holton III e Swanson (2005) apresentaram um arcabouço conceitual para a educação de adultos baseado em seis premissas que diferenciam os aprendizes adultos dos aprendizes crianças: (1) autoconceito: ser humano autodirigido; (2) experiência: acúmulo crescente de experiências, que se tornam um recurso valioso 
para a aprendizagem; (3) disposição para aprender: orientação progressiva para tarefas direcionadas ao desenvolvimento dos seus papéis sociais; (4) orientação para aprender: a perspectiva de tempo muda de "aplicação posterior do conhecimento" para "aplicação imediata do conhecimento"; (5) motivação interna para aprender; (6) necessidade de aprender.

Nesse sentido, as características do adulto-aprendiz devem orientar o design de programas de educação executiva, uma vez que o seu público-alvo é formado por adultos experientes, que têm a possibilidade de aplicar na prática os conhecimentos adquiridos, além de necessidade e motivação intrínseca para aprender. Na perspectiva da andragogia, a noção de "educar os adultos" é substituída pela ideia de "auxiliá-los a aprender". Considerando que a andragogia é uma filosofia educacional centrada no aprendiz, os professores assumem o papel de mentores e guias que auxiliam o desenvolvimento dos estudantes (FORREST III; PETERSON, 2006). Ao abordar esse assunto, Dewey (1979, p. 43) afirma que aprender é próprio do estudante: só ele aprende e por si; portanto, a iniciativa lhe cabe. Mas o professor deve ser o seu guia e, nesse sentido, precisa conhecer as suas experiências passadas, expectativas, desejos e interesses, fatores que terão uma forte influência no desenvolvimento do seu processo de reflexão e de aprendizagem. Na sua proposta de educação problematizadora, Freire (1978, p. 78) enfatiza que “o educador já não é o que apenas educa, mas o que, enquanto educa, é educado, em diálogo com o educando que, ao ser educado, também educa". Ambos se tornam, assim, sujeitos de um processo de crescimento conjunto, cuja base é a prática dialógica.

Na opinião de Schön (1987), é necessário reconceitualizar o papel do professor, que deve assumir uma função de orientador. Na sua proposição do ensino prático reflexivo, a legitimidade do orientador não depende das suas relações acadêmicas ou da sua proficiência como palestrante, mas do talento artístico da sua prática. Ele/a precisam ser mais ativos, promovendo diálogo entre os estudantes e desempenhando o papel de coach em vez do professor tradicional. Conforme o autor, quando o professor e o estudante estabelecem um diálogo efetivo, a aprendizagem é transformada em reflexão sobre a ação, que promove a descoberta de novos significados e formas de interpretação e resolução de problemas. Nesse contexto, o professor é um profissional reflexivo e, como tal, cria um diálogo contínuo de ações e palavras, reflexão-na-ação e reflexão sobre a ação mútuas, engajando o executivo em sala e orientando o seu processo reflexivo. O profissional reflexivo tem a capacidade para encontrar sentido nas situações incertas, únicas ou conflitantes da prática profissional. Enquanto profissional reflexivo, o professor torna-se um modelo para os estudantes, particularmente quando ele/a reflete publicamente sobre o seu próprio conhecimento-naação e instiga os estudantes a fazerem o mesmo. 
$\mathrm{Na}$ medida em que o professor reconhece o papel ativo dos estudantes em sala de aula e tenciona encorajar o intercâmbio entre ação e reflexão, ele/a deveriam adotar estratégias educacionais que exploram as experiências vividas pelos executivos como uma fonte de aprendizagem. Micromundos, estudos de caso e dramatização estão entre as estratégias que os professores usam para motivar ação e reflexão por meio da simulação de situações do mundo real (DEWEY, 1933; FORREST III; PETERSON, 2006; KOLB, 1984; SCHÖN, 1987).

De acordo com Schön (1987), os micromundos ou mundos virtuais são representações construídas do mundo real da prática que comprimem o tempo e o espaço e criam oportunidades para a análise, exposição, teste e aperfeiçoamento dos modelos mentais usados para a resolução de problemas complexos por meio da prática da reflexão-na-ação e da reflexão sobre a ação. Esses ambientes de aprendizagem são capazes de (1) reproduzir as características essenciais da prática a ser aprendida, possibilitando a realização de experiências sem os riscos envolvidos em uma situação real; (2) facilitar a adaptação do ritmo e foco do trabalho conforme as necessidades dos estudantes e do professor; (3) possibilitar a repetição das ações quando necessário (SCHÖN, 1987). Existem muitos micromundos projetados para simular situações organizacionais e eles têm sido amplamente utilizados nos programas de desenvolvimento gerencial, uma vez que representam um instrumento essencial para o aperfeiçoamento das capacidades decisórias, sem os riscos e custos do mundo real.

A reprodução de situações reais nos programas de administração pode apoiar-se em diálogos sobre os desafios organizacionais, trabalhos em equipe, estudos de caso, dramatizações. O centro dessas metodologias é uma situação simulada, desenhada para criar experiências pessoais para os aprendizes, que servem para desencadear o seu processo de reflexão, inquirição e compreensão do mundo real, seguindo os princípios da aprendizagem vivencial.

Christensen (1981) analisa a aplicação de estudos de caso na educação executiva e defende que as discussões sobre situações reais constituem ferramentas efetivas para aumentar a prática da reflexão. O autor acredita que o estudo de caso coloca os estudantes em um modo ativo de aprendizagem, desafia-os a aceitar substancial responsabilidade pela sua própria educação e proporciona uma apreciação de primeira mão e experiência com a aplicação do conhecimento à prática. Na visão de Schön (1987), nas escolas de administração a prática reflexiva pode ser exercitada por meio dos estudos de caso. Os professores hábeis na aplicação desse método conhecem diversas maneiras de utilizá-lo com esse propósito, que incluem desde a compreensão das interdependências entre os diferentes conteúdos abordados ao longo do programa até a conexão dos referenciais teóricos com a realidade prática dos estudantes.

A dramatização é outra estratégia de ensino/aprendizagem comumente empregada com o propósito de facilitar o exercício da prática reflexiva. Dentre outros resultados relevantes, a 
dramatização é especialmente útil para promover um elemento essencial do pensamento crítico - a capacidade de enxergar as situações sob pontos de vista diferentes. A dramatização tem como foco um elemento central do pensamento crítico - a habilidade para assumir as perspectivas dos outros. $\mathrm{Na}$ dramatização, a intenção é auxiliar os aprendizes a explorar os filtros perceptivos e estruturas de interpretação da outra pessoa, trazendo ao nível consciente alguns dos sentimentos e emoções envolvidas no gerenciamento dessas contingências (BROOKFIELD, 1987). Em sua análise a respeito da dramatização como uma estratégia de ensino/aprendizagem sob a perspectiva da andragogia, Forrest III e Peterson (2006, p. 117) afirmaram:

\begin{abstract}
A sala de aula se transforma em um laboratório que une as experiências prévias e o conhecimento aprendido. Os estudantes podem agir, ver os resultados do que fizeram, refletir, revisar suas suposições e experimentar outras possibilidades. Como um bônus adicional, o processo de reflexão auxilia os estudantes mais experientes a identificar o que já sabem e o que precisam de mais informação.
\end{abstract}

O processo de aprendizagem do executivo também pode ser aperfeiçoado quando o professor integra diferentes tópicos e estimula a reflexão sobre padrões, interações e relacionamentos nas diferentes áreas do conhecimento e da prática, conforme sugerido por Bennis e O’Toole (2005), Light e Cox (2001) e Schön (1987). A esse respeito, Bennis e O’Toole (2005, p. 104) observaram que o curriculum dos programas de MBA "precisa ser infundido com questões e análises multidisciplinares, práticas e éticas que refletem os desafios complexos que os executivos enfrentam". Nessa perspectiva, o objetivo principal do professor é demonstrar as inter-relações entre as várias funções gerenciais e o modo como funcionam juntas. Caso contrário, os estudantes enfrentarão dificuldades para lidar com os problemas do mundo real, que requerem uma visão multidisciplinar. Dumas et al. (2000, p. 233) explicaram que "contrariamente ao currículo tradicional baseado em disciplinas que enfatiza conteúdos específicos, o currículo integrado é fundamentado em expectativas de performance que expõem conhecimento genérico, competências e hábitos que os estudantes esperam obter". Esses autores enfatizam que nessa proposta os professores têm que enfrentar o desafio de "sair fora dos silos para os quais foram treinados" (p. 249), o que vai ao encontro da observação de Schön (1987) de que na abordagem interdisciplinar o especialista precisa estar aberto ao diálogo com outras áreas do conhecimento.

Esses elementos são críticos para a atuação dos professores direcionada ao desenvolvimento de executivos efetivos. Eles precisam ser amplamente pesquisados, estudados, examinados e debatidos em resposta aos desafios e oportunidades para o desenvolvimento desses profissionais em programas de educação executiva.

\title{
Metodologia
}


Nesta pesquisa, foram seguidos os pressupostos das abordagens subjetivistas e adotou-se a pesquisa qualitativa. Os dados foram coletados por meio de vinte entrevistas semi-estruturadas com executivos matriculados em um programa de MBA Executivo nos Estados Unidos, classificado entre os cinco melhores do mundo. ${ }^{1}$ As entrevistas foram realizadas no período de abril a maio de 2004 e tiveram duração média de uma hora. Para manter a confidencialidade, o nome da instituição onde o programa investigado é ofertado não será mencionado. Da mesma forma, os vinte executivos entrevistados e as organizações nas quais trabalham não serão identificados. Cada executivo será referenciado com o uso de letras do alfabeto.

A seleção dos executivos foi realizada com base na abordagem da amostra intencional randômica, proposta por Patton (2002), uma vez que os executivos entrevistados foram selecionados de forma aleatória entre aqueles que estavam cursando o MBA Executivo investigado. Além da possibilidade de contribuir para o estudo, o acesso aos executivos e a sua disposição em colaborar com a pesquisa foram determinantes para a sua participação nas entrevistas.

Além das entrevistas, professores foram observados diretamente durante (1) quatro aulas em diferentes módulos do programa investigado; (2) todas as aulas de um dos módulos; (3) conversas informais com os estudantes durante intervalos e refeições.

De forma complementar, foi realizada a análise de documentos relacionados ao tema da pesquisa. A análise documental teve como base (1) documentos que apresentam os objetivos, a estrutura curricular e os métodos de aprendizagem adotados em programas de MBA Executivo e, em particular, no programa investigado; (2) textos, estudos de caso e exercícios aplicados em algumas das disciplinas do programa; (3) rankings de classificação dos melhores programas de MBA Executivo.

Os dados foram registrados durante todos os momentos de interação com os entrevistados em um diário de campo. Nesse diário, estão registradas as transcrições das entrevistas, as notas de campo (dados colhidos nas observações, entrevistas e análise documental) e as notas do pesquisador (reflexões e percepções subjetivas que emergiram durante o processo da coleta dos dados).

Os dados foram analisados com base nos princípios da análise de dados qualitativos propostos por Minayo (1998). A proposta dessa autora envolve dois níveis de interpretação: (1) a compreensão do marco teórico-fundamental para a análise, definido na fase exploratória da investigação; (2) o encontro com os fatos empíricos, que são o ponto de partida e de chegada de qualquer investigação. Os dados levantados em cada entrevista foram analisados com base nas categorias originárias da literatura e do interesse original da pesquisa, ampliadas e modificadas à

\footnotetext{
${ }^{1}$ Business Week (rankings publicados em 15/10/01, 20/10/03 e 24/10/05) e Financial Times (rankings publicados em 15/10/01, 11/10/02, 20/10/03 e 11/11/04).
} 
medida que novas categorias emergiram dos dados. As categorias que emergiram das entrevistas individuais foram então testadas em relação ao restante dos dados coletados.

\section{Apresentação e discussão dos resultados}

Os resultados da pesquisa indicam que a atuação dos professores no Programa de MBA Executivo tem influência relevante no desenvolvimento da capacidade dos executivos para tomar decisões efetivas em situações inesperadas, complexas e incertas com as quais se defrontam na sua prática profissional. Todos os executivos entrevistados avaliaram que o desenvolvimento dessa capacidade foi estimulado pelos professores ao longo do programa. Os elementos mais importantes da atuação dos professores na percepção desses executivos podem ser assim resumidos: (1) a aplicação dos princípios da aprendizagem vivencial e da andragogia, que propiciaram um equilíbrio entre o rigor científico e a relevância prática, entre ação e reflexão; (2) as características de profissional reflexivo; (3) o uso combinado de diferentes estratégias de ensino/aprendizagem; (4) a criação de oportunidades para o compartilhamento de experiências.

É possível identificar o movimento entre pensamento e ação proposto na abordagem da aprendizagem vivencial no programa de MBA quando os executivos aplicam na sua prática profissional as experiências e os conceitos abordados em aula, nos encontros com as equipes de aprendizagem e nas conversas informais; compartilham suas experiências pessoais e profissionais; analisam situações concretas do mundo organizacional retratadas nos estudos de caso. $\mathrm{O}$ fato de manter as atividades profissionais durante a realização do programa de MBA Executivo amplia as chances de os executivos praticarem o que aprendem. Esse é um fator importante para a efetividade do processo de aprendizagem, pois lhes permite aplicar os conteúdos e experiências compartilhados no contexto escolar nas suas atividades cotidianas de trabalho, testá-los e, muitas vezes, retornar à escola com novas alternativas a serem analisadas. Dessa forma, é possível afirmar que o ciclo da aprendizagem vivencial, descrito por Kolb (1984) como essencial para a aprendizagem vivencial efetiva, ocorre repetidamente na situação investigada.

Todos os executivos classificaram as situações nas quais foi possível estabelecer ligações entre os conteúdos e as experiências dos colegas e professores discutidos na escola e as suas experiências práticas como momentos de grande aprendizagem. A declaração da executiva T ilustra a percepção dos demais executivos sobre essa questão:

Eu penso que você aprende melhor quando sente que algo é realmente aplicável. É algo que você pode pessoalmente relacionar com e dizer aqui está um exemplo específico da minha experiência passada. Você pode aplicar essa aprendizagem a algo com que está lidando agora ou algo que é antecipado no futuro. Eu acho que o concreto é realmente a chave (...) Por isso, em um processo de aprendizagem é importante trazer exemplos de uma variedade 
Do mesmo modo que a abordagem vivencial, o perfil dos executivos participantes do programa de MBA facilitou a aplicação dos princípios da aprendizagem de adultos pelos professores. Todos são aprendizes adultos de acordo com a definição de Knowles et al. (2005): idade média de 37 anos; experiência de mais de cinco anos em funções executivas; continuidade da carreira profissional durante a realização do programa; decisão pessoal de fazer o MBA Executivo. A capacidade para explorar essas características influenciou a percepção dos executivos de que os professores assumiram o papel de guia (ou coach) no processo de aprendizagem. Essas percepções são exemplificadas pela executiva $\mathrm{K}$.

A capacidade mais importante de um professor é primeiro de tudo ter paixão pela educação. Meu pai é professor, e eu acho que finalmente compreendi o que ele queria dizer quando mencionava que a sua maior satisfação vinha quando o aluno compreendia algo, aprendia algo extremamente importante que poderia usar. Não se trata apenas de discursar, mas de encorajar o pensamento crítico, ensinar você como pensar e ampliar sua forma de pensar, não apenas lhe dando fórmulas. É claro, é importante aprender esse tipo de habilidade, mas mais importante é ensinar você como mover-se para frente na sua vida ou trabalho. O que você irá fazer diferente com relação ao problema em função desta experiência? Além disso, eu acho que eles se mantêm atualizados com o que está acontecendo no mundo real, o que é extremamente importante. (Executiva K, comunicação pessoal, 16 de abril de 2004)

O executivo $\mathrm{Q}$, que atua na área da educação, destaca a disponibilidade dos professores e a capacidade de transmitir aos estudantes a sensação de estarem $100 \%$ presentes, mesmo com uma agenda lotada com projetos de pesquisa, consultoria e diversas outras atividades paralelas.

Existem duas coisas: o entusiasmo, a energia e a motivação que eles trazem para a sala de aula e a capacidade de tornar as coisas compreensíveis de forma simples (...) Por exemplo, eu conheço muitos diretores e eu não conheço muitos deles tão ocupados como o diretor desta escola, ele está em todos os lugares. Mas, quando ele está na frente daquela sala ensinando, você pensa que a razão dele estar ali somos nós (...) e eu quase me sinto culpado se não sou tão entusiástico sobre o assunto como ele é. Então, para mim existe uma energia e entusiasmo, um tom que o professor define que, em alguns casos, é tão ou mais importante do que avaliá-los com base em critérios técnicos de ensino. (Executivo Q, comunicação pessoal, 27 de maio de 2004)

Os comentários da executiva $\mathrm{B}$ e do executivo $\mathrm{P}$ retratam a percepção dos demais executivos de que a atuação dos professores representou um dos elementos mais relevantes para a efetividade do programa.

Eu percebi que os professores ensinam com muito entusiasmo. Na minha longa viagem de volta para casa eu não consigo parar de pensar sobre o que o professor ensinou em sala, então eu aprendi bem daquela vez. Às vezes você aprende lendo, mas se a exposição em sala não é boa você fica desapontada. (Executiva B, comunicação pessoal, 30 de abril de 2004)

Existem duas coisas sobre os professores que eu realmente aprecio: uma delas é que você se sente como uma pessoa, você não tem a sensação de que eles estão lá em cima e você aqui embaixo, que é uma coisa à qual eu sou bem sensível. Mas de forma alguma, você sente 
As observações realizadas em algumas disciplinas complementam esses relatos e mostram que as ideias de Schön (1987) e Dewey (1979) - o papel do professor não é ensinar ao estudante o que ele precisa saber, mas orientar e guiar o seu processo de descoberta - estão presentes na atuação dos professores. A busca pelo equilíbrio entre a pesquisa científica, a sua prática profissional e as experiências dos executivos, com foco na relevância dos conteúdos teóricos para a prática profissional dos executivos são um indicativo do talento artístico (artistry) dos professores.

De acordo com os executivos e dados registrados durante as observações realizadas pelo pesquisador, os professores revelam o talento artístico (artistry) quando criam um ambiente que estimula os estudantes a compartilhar suas experiências; refletir sobre as suas próprias experiências; refletir sobre as experiências e ideias dos outros; ajustá-las à sua realidade profissional; desenvolver conversas reflexivas com as situações da prática e com os demais estudantes. Além disso, demonstram (1) sólidos conhecimentos sobre os conteúdos abordados, refletidos principalmente na coordenação dos debates, na diversidade de exemplos práticos e na segurança ao esclarecer as dúvidas e responder aos questionamentos dos executivos; (2) experiência consistente e atualizada na sua área de especialização, que enriquece o repertório de experiências usado na prática reflexiva; (3) grande entusiasmo, energia e paixão em sala de aula; (4) capacidade de sintetizar as atividades de cada encontro; (5) humildade para reconhecer quando não têm resposta para determinada questão.

Entretanto, durante as observações foi possível identificar a falta de uma competência dos professores enquanto profissionais reflexivos, que é descrita por Schön (1987, p. 302) como a capacidade para "testar publicamente suas convicções, expondo julgamentos negativos e revelando confusões ou dilemas". Ao fazer isso, "eles terão maior possibilidade para expandir suas competências para refletir na e sobre a ação, por conseguinte, maior possibilidade para dar e receber evidência das mudanças de compreensão das quais depende a reflexão recíproca".

Outro elemento relevante na atuação do professor é a diversidade de estratégias de ensino/aprendizagem usadas para encorajar os executivos a associar teoria e prática e para criar conversações reflexivas: estudos de caso, dramatização, simulação e exposição dialogada, assim como trabalho em equipe. Essas estratégias são combinadas pelos professores de acordo com os objetivos de cada módulo, a natureza dos conteúdos e as oportunidades de aprendizagem a partir das experiências dos executivos. Para ilustrar o uso de estudos de caso, seguem alguns comentários (registrados como notas de campo) de um professor durante a apresentação de um caso: "(a) Vocês precisam prestar atenção aos fatores sistêmicos envolvidos neste caso. (b) De que forma você lida 
com os desafios de ser um CEO da sua organização x ser um cidadão da sociedade? (c) Como você protege as pessoas sob sua responsabilidade em situações de crise como aquelas enfrentadas pela Enron, Sunbean, Worldcom? (d) O que nós fizemos e o que estamos fazendo para prevenir outros casos como o da Enron?"

A citação do executivo $O$ representa a percepção comum dos executivos sobre a contribuição dos estudos de caso para o desenvolvimento da prática reflexiva. A "mão invisível" citada por esse executivo corresponde, novamente, às ideias Schön (1987) e Dewey (1933) de que a função maior do professor é guiar o processo de descoberta do estudante.

Para os instrumentos básicos de gerenciamento, o método do estudo de caso é realmente valioso. Ele lhe permite colocar-se em diferentes situações e pensar se eu estivesse nesta situação, o que eu faria? Quais serão os efeitos desta decisão? É surpreendente como diferentes pessoas trazem diferentes opções. Ele o faz pensar como eu não pensei sobre isto antes? Existem professores realmente bons em estudos de caso. Eles são a mão invisível guiando as discussões. (Executivo O, comunicação pessoal, 10 de abril de 2004)

A contribuição das estratégias de simulação e dramatização para o desenvolvimento da prática reflexiva está presente na declaração da executiva $\mathrm{T}$.

\footnotetext{
Eu acho que você pode dramatizar as situações por meio de exercícios em pequenos grupos. Você lhes dá um cenário e a tarefa é o que você faria se estivesse nessa situação? Mesmo que seja um estudo simulado, sentir algumas das emoções o faz levar para casa muitas das lições relevantes, mais do que se tivesse alguém lhe falando. Mesmo sabendo que não é real, pode ser simulado de forma que o ajudará a ver isto. Eu acho que reforça a lição na sua cabeça. (Executiva T, comunicação pessoal, 16 de abril de 2004)
}

Adicionalmente a essas estratégias de ensino/aprendizagem, as interações entre professores e estudantes e entre os próprios estudantes foram consideradas essenciais para o processo de aprendizagem, na medida em que essas interações estimulam a prática da inquirição e da reflexão. Todos os executivos relataram que as oportunidades para compartilhar experiências constituíram um dos processos de aprendizagem mais importantes já vivenciados por eles.

Ao compartilhar experiências e ouvir histórias sobre diferentes modelos mentais e perspectivas para tratar questões iguais ou similares, os executivos se sentiram encorajados a refletir sobre os seus próprios pensamentos, decisões e ações. Como resultado, o programa contribuiu não apenas para o conhecimento sobre as práticas gerenciais, mas também para o desenvolvimento de um pensamento sistêmico, novos modelos mentais e abordagens críticas e criativas para a compreensão e resolução de problemas. Os depoimentos do executivo I e do executivo O revelam as percepções comuns dos executivos sobre o processo de compartilhar experiências e aprender com elas.

$\mathrm{Na}$ minha equipe eu tenho pessoas de diferentes setores e nós inspiramos uns aos outros, nos complementamos, então eu aprendi muito com os meus colegas (...). Esse programa não é sobre colocar a questão certa no quadro, é sobre pensar como você analisaria a 

no jantar ou tomando uma cerveja é onde nós aprendemos mais. (Executivo I, comunicação pessoal, $1^{\circ}$ de maio de 2004)

Na sua organização, você não tem a oportunidade de conversar com pessoas no mesmo nível que você, outros CEOs. Diferentes experiências na mesma classe estimulam muitas discussões interessantes (...). Na nossa classe nós temos CEOs e executivos de alto nível que têm uma experiência imensa, são mais de 1000 anos de experiência em sala. (Executivo O, comunicação pessoal, 10 de abril de 2004)

O processo de compartilhar experiências é facilitado pela ênfase que os professores atribuem aos trabalhos em equipe. As equipes de trabalho e a estrutura de suporte às atividades em equipe constituem característica fundamental do Programa de MBA Executivo analisado e é comum na maioria dos programas americanos e europeus. Enquanto micromundos que reproduzem situações reais, as equipes de trabalho preparam os estudantes para identificar e superar as rotinas defensivas que influenciam as pessoas a reforçar mutuamente as crenças vigentes, suprimir as discordâncias e se isolar daqueles com visões diferentes das suas. O executivo D resumiu a percepção geral dos executivos sobre a aprendizagem em equipe no decorrer do programa.

\begin{abstract}
Eles têm diferentes experiências das que você tem, e eles compartilharão essas experiências com você. Por causa disto, se você está aberto ou não está aberto, às vezes isto o força a olhar para as coisas de forma diferente. Mesmo nos pequenos grupos, é muito parecido com o trabalho, e é obviamente por isso que a escola faz isso. Todos não irão concordar, todos terão um nível diferente de expertise, um nível diferente de conhecimento e diferentes opiniões em termos de como superar o desafio. (Executivo D, comunicação pessoal, 15 de maio de 2004)
\end{abstract}

Os executivos indicaram outras práticas de aprendizagem utilizadas pelos professores paralelamente ao trabalho em equipe: (1) a abertura participativa, que permite a livre expressão do pensamento; (2) a abertura reflexiva, que estimula a reflexão sobre o próprio pensamento e sobre o pensamento das outras pessoas; (3) o exercício do diálogo, cuja essência é a liberdade para expor ideias e opiniões sem temer repercussões negativas.

A relevância atribuída pelos executivos às oportunidades de desenvolver a prática reflexiva não apenas no nível individual, mas também na esfera coletiva foi um resultado importante da pesquisa de campo, que tem respaldo nos referenciais teóricos. Segundo Light e Cox (2001, p. 45), "a aprendizagem não é um processo de construção do conhecimento individual em uma situação social e culturalmente estável, mas é fragmentado, incerto e em mudança porque é construído num mundo cada vez mais fragmentado, incerto e em mutação".

As interações entre professor e estudantes, bem como entre os próprios estudantes, têm um papel essencial na efetividade do processo de aprendizagem, na medida em que essas interações fomentam o desenvolvimento da capacidade dos estudantes para rever modelos mentais individuais e coletivos e práticas profissionais por meio da inquirição e da reflexão (LISSACK; ROSS, 1999; 
MEYERS, 1991; MEZIROW, 1990; RAELIN, 2002; ROGLIO; LIGHT, 2009; SCHÖN, 1983). A esse respeito, Mezirow (1990) afirmou que é por meio do diálogo que nós tentamos entender - e aprender - o que é válido nas afirmações feitas por outros e tentar chegar a uma validação consensual para nossas próprias afirmações. Na percepção de Raelin (2002, p. 66):

Na sua forma pública, a prática reflexiva é associada aos diálogos de aprendizagem. Esse tipo de discussão, antes de constituir uma troca de afirmações sobre pontos de vista, traz à tona - na presença segura de pares confiáveis - dados sociais, políticos e emocionais que emergem da experiência direta entre eles. Frequentemente esses dados são precisamente aqueles que podem estar bloqueando a efetividade do processo decisório.

Em sua análise sobre os relacionamentos dos estudantes em sala de aula, Meyers (1991, p. 31) observou que "confrontar as perguntas e conclusões dos colegas, frequentemente diferentes das suas próprias conclusões, ajuda a remover os estudantes das suas percepções egocêntricas do mundo". Essas interações acontecem tanto no contexto formal da escola como nas situações informais vivenciadas dentro e fora dos muros escolares. De acordo com Knowles (1984), a vida associada (ou de clube) constitui uma oportunidade valiosa para a consolidação da aprendizagem.

Uma crítica dos executivos ao programa é a carência de estratégias direcionadas ao desenvolvimento mais aprofundado do autoconhecimento. A afirmação da executiva $\mathrm{C}$ resume as críticas dos executivos.

\footnotetext{
Nós não fazemos coisas no programa como avaliação 360, Myers-Briggs ou algo nesse sentido. E eu não estou certa do porquê (...). Eu considero que existe espaço para isso no programa e penso que as pessoas ficariam muito satisfeitas. Essa é a chance que temos para trabalhar nisso. (Executiva D, comunicação pessoal, 5 de maio de 2004)
}

Os executivos avaliaram que em programas de MBA Executivo os professores possuem as condições ideais para promover atividades que lhes possibilitem (1) mapear os seus pontos fortes e fracos; (2) definir estratégias para promover o seu crescimento pessoal e profissional. Além disso, à medida que sobem na hierarquia da organização, eles sentem que recebem menos feedback sobre o seu desempenho. Em algumas entrevistas, percebe-se um sentimento de isolamento.

Os resultados da pesquisa revelaram elementos que precisam ser seriamente considerados por professores e administradores na revisão ou implementação de programas de educação executiva que tenham como um propósito desenvolver executivos competentes para trabalhar e prosperar diante da incerteza, multiplicidade e interdisciplinaridade que caracterizam os desafios da sociedade atual.

\section{Conclusões}

Neste artigo, foram identificados elementos relevantes na atuação do professor no desenvolvimento da capacidade dos executivos para tomar decisões efetivas em situações 
inesperadas, complexas e incertas com as quais se defrontam na sua prática profissional. Após identificar esses elementos no referencial teórico, buscou-se confirmá-los por meio de uma pesquisa qualitativa em um Programa de MBA Executivo. A síntese desses elementos é apresentada no

Quadro 1.

Quadro 1

Elementos que facilitam o desenvolvimento da capacidade dos executivos para tomar decisões efetivas.

\begin{tabular}{|c|c|c|}
\hline Elemento & Definição & Programa MBA Executivo \\
\hline $\begin{array}{c}\text { Teoria da } \\
\text { aprendizagem } \\
\text { vivencial }\end{array}$ & $\begin{array}{l}\text { O professor promove a reflexão sobre } \\
\text { situações vivenciadas pelos executivos, } \\
\text { estimulando-os a identificar os modelos } \\
\text { mentais aplicados nos seus processos } \\
\text { decisórios; as consequências geradas pelas } \\
\text { suas decisões sobre os indivíduos, as } \\
\text { organizações e a sociedade; lições que podem } \\
\text { ser extraídas dessas consequências. }\end{array}$ & $\begin{array}{l}\text { - O ciclo da aprendizagem vivencial acontece quando os } \\
\text { executivos aplicam na sua prática profissional as experiências e } \\
\text { os conceitos abordados em aula, nos encontros com as equipes } \\
\text { de aprendizagem e nas conversas informais; compartilham suas } \\
\text { experiências pessoais e profissionais; analisam situações } \\
\text { concretas do mundo organizacional simuladas nos estudos de } \\
\text { caso. } \\
\text { - A manutenção das atividades profissionais durante a realização } \\
\text { do programa de MBA Executivo constitui um elemento } \\
\text { facilitador para a aprendizagem vivencial. }\end{array}$ \\
\hline $\begin{array}{l}\text { Princípios da } \\
\text { andragogia }\end{array}$ & $\begin{array}{l}\text { Princípios que caracterizam a aprendizagem de } \\
\text { adultos: autoconceito; experiência; disposição } \\
\text { para aprender; orientação para aprender; } \\
\text { motivação interna para aprender; necessidade } \\
\text { de aprender. }\end{array}$ & $\begin{array}{l}\text { - O motivo principal para realizar o MBA Executivo é a } \\
\text { consciência dos executivos sobre a relevância e a necessidade de } \\
\text { aprendizagem e aperfeiçoamento contínuos. } \\
\text { - A responsabilidade pelo processo de aprendizagem é } \\
\text { compartilhada entre alunos e professores. } \\
\text { - O repertório de experiências enriquece o processo de } \\
\text { aprendizagem. } \\
\text { - Possibilidade de aplicação imediata de conhecimentos. }\end{array}$ \\
\hline $\begin{array}{c}\text { Professor como } \\
\text { profissional } \\
\text { reflexivo }\end{array}$ & $\begin{array}{l}\text { Enquanto profissional reflexivo, o professor } \\
\text { cria um diálogo contínuo de ações e palavras, } \\
\text { reflexão-na-ação e reflexão sobre a ação } \\
\text { mútuas, engajando o executivo em sala e } \\
\text { orientando o seu processo reflexivo. O } \\
\text { professor torna-se um modelo de profissional } \\
\text { reflexivo para os executivos. }\end{array}$ & $\begin{array}{l}\text { - O talento artístico (artistry) dos professores se revela no } \\
\text { processo de motivação dos executivos para compartilhar suas } \\
\text { experiências; refletir sobre as suas próprias experiências; refletir } \\
\text { sobre as experiências e ideias dos outros; ajustá-las à sua } \\
\text { realidade profissional; desenvolver conversas reflexivas com as } \\
\text { situações da prática e com os demais executivos. } \\
\text { - Falta aos professores a capacidade para testar publicamente } \\
\text { suas convicções. }\end{array}$ \\
\hline $\begin{array}{c}\text { Estratégias de } \\
\text { ensino/aprendiz } \\
\text { agem }\end{array}$ & $\begin{array}{l}\text { Micromundos, estudos de caso e dramatização } \\
\text { motivam ação e reflexão com base na } \\
\text { simulação de situações reais, principalmente do } \\
\text { contexto organizacional. }\end{array}$ & $\begin{array}{l}\text { - O uso combinado de estratégias de ensino/aprendizagem } \\
\text { encoraja os executivos a associar teoria e prática e estimula } \\
\text { conversações reflexivas. } \\
\text { - As estratégias são combinadas pelos professores de acordo com } \\
\text { os objetivos de cada módulo, a natureza dos conteúdos e as } \\
\text { oportunidades de aprendizagem a partir das experiências dos } \\
\text { executivos. } \\
\text { - Existe a necessidade de promover atividades que possibilitem } \\
\text { aos executivos mapear os seus pontos fortes e fracos, bem como } \\
\text { definir estratégias para promover o seu crescimento pessoal e } \\
\text { profissional. }\end{array}$ \\
\hline $\begin{array}{c}\text { Experiências } \\
\text { compartilhadas }\end{array}$ & $\begin{array}{l}\text { As interações entre professor e estudantes, bem } \\
\text { como entre os próprios estudantes, têm um } \\
\text { papel essencial na efetividade do processo de } \\
\text { aprendizagem, na medida em que fomentam o } \\
\text { desenvolvimento da capacidade para rever } \\
\text { modelos mentais individuais e coletivos e } \\
\text { práticas profissionais por meio da inquirição e } \\
\text { da reflexão. }\end{array}$ & $\begin{array}{l}\text { - O compartilhamento de experiências e histórias sobre } \\
\text { diferentes modelos mentais e perspectivas para tratar questões } \\
\text { iguais ou similares encoraja a reflexão sobre os próprios } \\
\text { pensamentos, decisões e ações. } \\
\text { - O processo de compartilhar experiências é facilitado pela } \\
\text { ênfase que os professores atribuem aos trabalhos em equipe e } \\
\text { outras práticas de aprendizagem: abertura participativa; abertura } \\
\text { reflexiva; exercício do diálogo. }\end{array}$ \\
\hline
\end{tabular}

Fonte: Elaborado com base nos referenciais teóricos e nos resultados da pesquisa de campo.

Uma conclusão da investigação é que os princípios da aprendizagem vivencial devem orientar as atividades dos programas de MBA Executivo, em especial nas situações em que os executivos não necessitam interromper as suas atividades profissionais enquanto cursam o 
programa. Nessas situações, o professor tem condições para encorajar o processo de aprendizagem a partir da experiência, considerando-se que é possível aprender com experiências primárias que trazem a realidade da prática profissional para dentro da sala de aula e propiciam aos estudantes uma visão realista do mundo dos negócios.

Outra conclusão é que a andragogia é a abordagem ideal quando os estudantes possuem o perfil dos executivos no programa investigado. Esse perfil é característico dos programas direcionados à educação executiva. Cada uma das premissas apresentadas por Knowles et al. (2005) é apropriada às características dos executivos.

A relevância de o professor ser um profissional reflexivo é outro importante resultado advindo desta pesquisa. Evidências do talento artístico (artistry) dos professores, listadas no item que mostra os resultados do trabalho de campo, deveriam ser seriamente consideradas pelos programas de MBA Executivo. O desenvolvimento desse talento artístico (artistry) deve constituir um esforço conjunto de professores e administradores nesses programas, incluindo programas de treinamento com esse propósito.

A diversidade de estratégias de ensino/aprendizagem usadas no programa investigado foi avaliada como um elemento importante para que o professor possa estimular os executivos a relacionar teoria e prática. Por isso, devem ser intencional e explicitamente aplicadas pelos professores para o desenvolvimento de processos decisórios efetivos. Em particular, o processo de compartilhar experiências precisa ser fortemente encorajado nas interações formais e informais, tendo em vista que os executivos o avaliaram como uma das mais valiosas práticas de aprendizagem que já vivenciaram.

Com relação às críticas sobre a carência de estratégias direcionadas ao exercício do autoconhecimento, sugere-se que, de acordo com as especificidades de cada módulo, os professores adotem instrumentos desenvolvidos para esse fim (ROGLIO; LIGHT, 2009): NEO PI-R (Neuroticism, extroversion, openness personality inventory revised) (COSTA; MCCRAE, 1992); MBTI (The Myers Briggs type indicator) (MYERS; MYERS, 1980, 1995); FIRO-B (Fundamental interpersonal relationship orientation-behavior) (SCHUTZ, 1958); Avaliação 360. Ao mesmo tempo, propõe-se a criação de um módulo específico para tratar do assunto.

As reflexões apresentadas neste artigo sobre desafios e oportunidades para programas de MBA Executivo podem contribuir para o debate - incitado por Bennis e O'Toole (2005), Gosling e Mintzberg (2003), Ghoshal (2005), Grey (2004), Reynolds e Vince (2004) - sobre o design de programas de educação executiva e os seus impactos sobre o indivíduo, a organização e a sociedade. A atuação do professor contribui para aumentar a efetividade da educação executiva e 
constitui um fator a ser seriamente considerado pelos programas que querem ter sucesso em prover as organizações e a sociedade com executivos efetivos.

Os elementos da atuação do professor aqui analisados podem ser decisivos para o desenvolvimento de executivos efetivos. De modo particular, esses elementos constituem referenciais para o desenvolvimento e o aperfeiçoamento de programas de educação executiva no Brasil, sobretudo ao se considerar que o Programa de MBA Executivo investigado figura entre os melhores do mundo e que os elementos analisados não se restringem a um contexto cultural específico.

\section{Referências}

BENNIS, W.; O'TOOLE, J. How business schools lost their way. Harvard Business Review, v. 83, n. 5, p. 96-104, May 2005.

BROOKFIELD, S. D. Developing critical thinkers: challenging adults to explore alternative ways of thinking and acting. San Francisco: Jossey-Bass Publishers, 1987.

CHRISTENSEN, R. Teaching and the case method. Boston: Harvard Business School, 1981.

CURRIE, G.; KNIGHTS, D. Reflecting on a critical pedagogy in MBA education. Management Learning. Thousand Oaks, v. 34, n. 1, p. 27-50, Mar 2003.

DEWEY, J. How we think: a restatement of the relation of reflective thinking to the educative process. Boston: Heath, 1933.

DEWEY, J. Como pensamos: como se relaciona o pensamento reflexivo com o processo educativo: uma reexposição. 4. ed. São Paulo: Nacional, 1979.

DRUCKER, P. F. What makes an effective executive. Harvard Business Review, v. 82, n. 6, p. 58-63, June 2004.

DUMAS, C.; BLODGETT, M.; CARLSON, P.; PANT, L.; VENKA, M. Revitalizing the MBA for the new millennium: a collaborative action research. International Journal of Value-Based Management, v. 13, n. 3, p. 229-253, Springer 2000.

FREIRE, P. Pedagogia do oprimido. 6. ed. Rio de Janeiro: Paz e Terra, 1978.

FORREST III, S. P.; PETERSON, T. O. It's called andragogy. Academy of Management Learning \& Education, v. 5, n. 1, p. 113-122, 2006.

GHOSHAL, S. Bad management theories are destroying good management practices. Academy of Management Learning \& Education, v. 4, n. 1, p. 75-91, 2005.

GREY, C. Reinventing business schools: the contribution of critical management education. Academy of Management Learning \& Education, v. 3, n. 2, p. 178-186, 2004. 
GHOSHAL, S.; ARNZEN, B.; BROWNFIELD, S. A learning alliance between business and business schools: executive education as a platform for partnership. California Management Review, v. 35, n. 1, p. 50-67, 1992.

GOSLING, J.; MINTZBERG, H. The five minds of a manager. Harvard Business Review, v. 81, n. 11, p. 54-64, 2003.

KOLB, D. Experiential learning: experience as the source of learning and development. Englewood Cliffs: Prentice-Hall, 1984.

KNOWLES, M. S.; Holton III, E. F.; SWANSON, R. A. The adult learner. 6. ed. San Diego: Elsevier, 2005.

KNOWLES, M. S. Andragogy in action: applying modern principles of adult learning. San Francisco: Jossey-Bass, 1984.

LIGHT, G.; COX, R. Learning and teaching in higher education: the reflective professional. London: Sage, 2001.

LISSACK, M.; ROSS, J. The next common sense: mastering corporate complexity through coherence. London: Nicholas Brealey Publishing, 1999.

MEYERS, C. Teaching students to think critically. 5. ed. San Francisco: Jossey Bass, 1991.

MEZIROW, J. Fostering critical reflection in adulthood. San Francisco: Jossey-Bass, 1990.

MINAYO, M. C. O desafio do conhecimento: pesquisa qualitativa em saúde. 5. ed. São Paulo: Hucitec, 1998.

PATTON, M. Q. Qualitative research and evaluation methods. 3. ed. Thousand Oaks: Sage, 2002.

RAELIN, J. A. "I don't have time to think!" versus the art of reflective practice. Reflections, v. 4, n. 1, p. 66-79, Fall 2002.

RAELIN, J. A.; COGHLAN, D. Developing managers as learners and researchers: using action learning and action research. Journal of Management Education, v. 30, n. 5, p. 670-689, 2006.

REYNOLDS, M.; VINCE, R. Critical management education and action-based learning: synergies and contradictions. Academy of Management Learning \& Education, v. 3, n. 4, p. 442-456, 2004.

ROGLIO, K. D; LIGHT, G. Executive MBA Programs: the development of the reflective executive. Academy of Management Learning and Education, 2009, In-Press.

SCHÖN, D. A. The reflective practitioner: how professionals think in action. New York: Basic Books, 1983.

SCHÖN, D. A. Educating the reflective practitioner. San Francisco: Jossey Bass, 1987. 
SMITH, G. F. Beyond critical thinking and decision making: teaching business students how to think. Journal of Management Education, v. 27, n. 1, p. 24-51, 2003.

SMITH, P. Action learning and reflective practice in project environments that are related to leadership development. Management Learning, v. 32, n. 1, p. 31-48, 2001. 